\title{
Terraced landscapes of the Shouf Biosphere Reserve (Lebanon): analysis of geomorphological variables
}

\author{
Federica Corrieri ${ }^{1} \cdot$ Francesco Piras $^{1} \cdot$ Marwa Abou Assi $^{2} \cdot$ Marco Focacci $^{3}$. \\ Leonardo Conti ${ }^{1}$ (D)
}

Received: 27 April 2021 / Revised: 11 May 2021 / Accepted: 17 May 2021 /

Published online: 25 May 2021

(c) The Author(s) 2021

\begin{abstract}
This work aims to characterize the agricultural heritage system surrounding the Shouf Biosphere Reserve (SBR) in Lebanon, through a landscape analysis based on assessing current ecosystems. In the past, the SBR landscape was intensively terraced and cultivated to produce many different crops. Today, although the terraced surface has been reduced, it is still a characteristic of the area, encouraging the quality of the landscape and increasing local biodiversity. During and after the war (the 1950s), the migration of population caused the abandonment of many cultivated terraces with the loss of a wide range of ecosystem services. This trend should be reversed to ensure these ecosystem services. The diversity of the land uses, and the richness of fauna and flora species raise the importance of the role of the SBR in maintaining the complex ecosystem and increasing its resilience capacity. The objectives of preserving biocultural diversity and traditional local agricultural practices can be achieved through sustainable development policies for the dynamic conservation of landscapes. In this study, it was shown that distance from roads to terraced areas is a fundamental factor in the preservation and maintenance of terraces. As well as the aspect and the slope influence the positioning of the terraces and therefore the species cultivated on them.
\end{abstract}

Keywords Terraces $\cdot$ Landscape $\cdot$ Biodiversity $\cdot$ Resilience

\section{Introduction}

Terraced landscapes represent a very ancient cultural practice that goes back to the Bronze Age (about 3700 years ago) in steep hilly or mid mountainous areas throughout the Mediterranean region to create arable land opportunities in steep mountain areas (Aalen 2001; Dunjó et al. 2003; Modica et al. 2017, Lasanta et al. 2017). They are an important part of the many cultural landscapes existing in the world resulting form the modification of the natural basis developed by rural communities (Agnoletti 2014).

Communicated by Mauro Agnoletti.

Leonardo Conti

leonardo.conti@unifi.it

Extended author information available on the last page of the article 
The terraces provide a wide range of ecosystem services: they create fertile soil and favorable microclimate conditions for crops; slow down the water runoff to irrigate the crops and fill local reservoirs for irrigation during dry spells; support biodiversity in the microhabitats provided by the stone walls; act as firebreaks in forested mountain landscapes (Arnaez et al. 2011; Tarolli et al. 2014).

Although there are several types of terraces, they share some basic features. The principle is almost always to replace a slope by steps with horizontal "treads" of soil and vertical or near-vertical "risers" in the form of retaining walls. The walls are made of stone extracted in the process of making the terraces or quarried in the immediate vicinity. The amount of work necessary, and its cost, depends on slope, rock type, abundance or paucity of soil, nature of the vegetation, and type of terrace under construction (Lewis 1953; Agnoletti et al. 2015).

In the Shouf Biosphere Reserve (SBR), the landscape is characterized by terraces that have undergone cultural changes over the centuries because many systems have been abandoned. The slopes around the municipalities in the Shouf Biosphere Reserve landscape were intensively terraced and cultivated since ancient times to produce vines, olives, mulberries, walnut, and almond trees in addition to figs and grains. Agriculture terraces were very much used in the past to produce, in particular, mulberry trees for the silk industry (Diane and Brandon 2010, 2019).

The percentage of land that these trees took up increased from about $10 \%$ to more than $40 \%$ during the same eighty-year period. With mulberry trees covering so much of the arable land during the last quarter of the nineteenth century, silk naturally came to play a dominant role in the agricultural economy of the SBR (MOA 2020). After 1945, the sericulture industry declined sharply and mulberry cultivation was marginalized (Abu-Izzeddin 2017). The mulberry trees were replaced by citrus on the coast and tobacco, vines and fruit trees in the mountainous regions (FAO 2020a). The presence of several grapes and olive presses from Roman times is an indicator of the ancient culture of terraced crops in this area.

In 1950 phylloxera has attacked the vine of higher Shouf; from 1950 till 1970, many vines were lost, in addition to the lands abandoned for the civil war that started in 1948 (Markou and Kavazis, 2006). Since 1970, apple and cherry trees were included in the agriculture of the site, and now considering the report of FAO $(2020 a, b)$ on the state of plant genetic resources for food and agriculture, the apple in Lebanon comes in the second place (9390 Ha, 113,300 tons) after olive.

After the war, agriculture never returned to its old glory but never thought away totally because it is an old tradition for the Lebanese population, especially for the rural community. Lands are considered heritage treasures from ancients that the Lebanese population should conserve even if it is not worth economically. All the villages' inhabitants have agricultural parcels and terraces inherited from their antecedents and produce food goods often for self-consumption (Ghattas et al. 2013). However, they still conserve the land because it means their pride, roots and also a second income source.

In the scenario of sustainable development for 2030, proposed by the United Nations (2015), sustainable and resilient agricultural and food production systems are hoped for, capable of increasing productivity, supporting and maintaining ecosystems, and improving the quality of the territory. The multifunctionality of the rural landscape, ecosystem services in favor of human well-being, and the development of production technologies with low environmental impact are key elements for solving problems and searching for solutions. To safeguard fragile rural contexts, as the SBR area, changing from an ecological and socio-economic perspective, it is necessary to find new production models capable 
of directing the respective communities towards resilience, food, energy, and technological sovereignty (Ghattas et al. 2013; Di Fazio and Modica 2018).

For these reasons, the policies of the SBR should be aimed at the protection and enhancement of the agricultural terraced systems that have a strategic role in the conservation of biodiversity, in maintaining local identity, in addition to the well-known agricultural and hydrogeologic functions (Laureano 2007). This study aims to provide a territorial analysis of the terraced areas, offering indications on the terraced areas' distribution based on the slope, aspect and altitude, defyning the spatial scale where agrobiodiversity developed, as part of the more general concept of biocultural diversity characterizing landscape resulting from the coevolution between mand and nature.

\section{Materials and methods}

\section{The study area}

The study area is located in Shouf district (Fig. 1), one of the six districts of Mount Lebanon Governorate. The site is composed of four villages. Each one has its own municipality; they are extended on the higher top of Shouf mountain on the board of Bekaa Governorate.

The site is extended over 4 municipalities, covering 3.809 ha:

- Maaser El Shouf, first municipality from the north side;

- El Khreibeh, the municipality is surrounded by four villages that remain four roads connecting the centre of the village to the neighbors.

- Mrousti is $67 \mathrm{~km}$ far from Beirut with two main roads coming to the village, one from Khreibehside and the second one from Jbaa having borders with Msaser el Shouf also without main road connecting them;
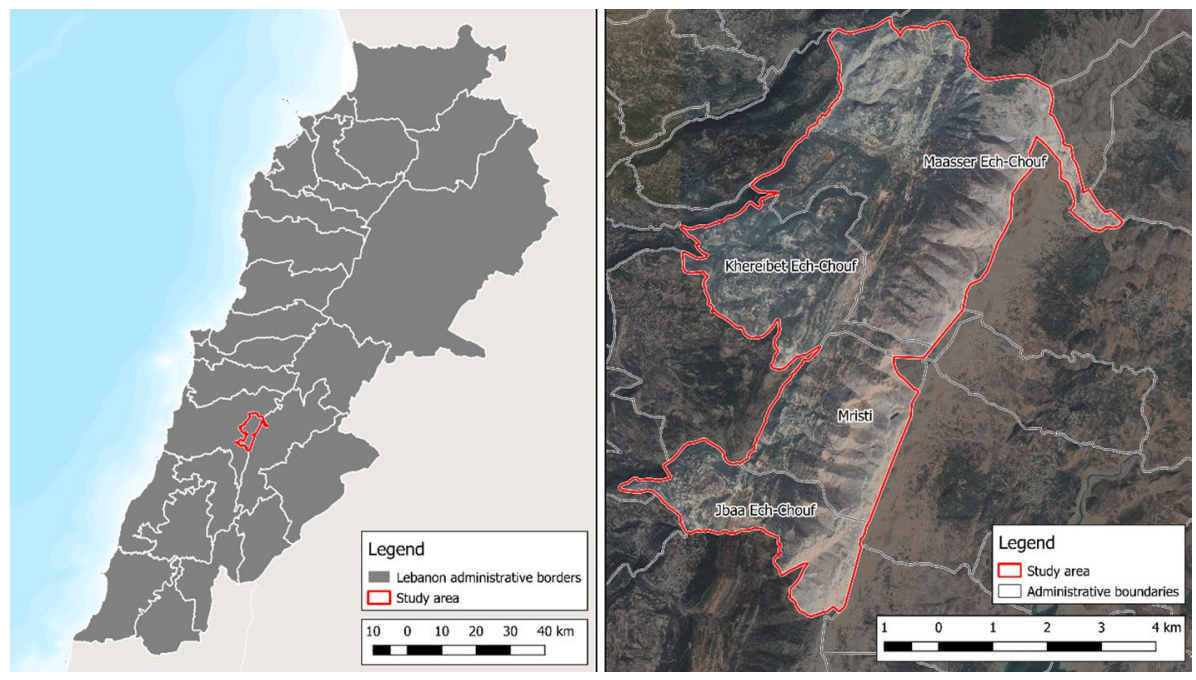

Fig. 1 Framework of the study area 
- Jbaa is one of the municipalities near Jezzine district; two main roads arriving to the village, one from the side of Niha Shouf (last village of Shouf district) and another from the side of Mrousti.

The altitude of the site starts from $800 \mathrm{~m}$ up to $1800 \mathrm{~m}$ and some points it can arrive at $2000 \mathrm{~m}$ on the top of the mountain, where we can find the reserve of cedars in Maaser el Shouf.

A typical Mediterranean climate with four distinct seasons; the average temperature of the warmest month (August) is $20^{\circ} \mathrm{C}$, and the coldest month (Jan) is $4{ }^{\circ} \mathrm{C}$. The summers are warm dry, while winters are cool and wet.

The study area has within it a reserve called Al Shouf Cedar Nature Reserve. It is located on the slopes of Jebel Baruk mountain and has an area of $550 \mathrm{~km}^{2}$ and represents almost $5.3 \%$ of the Lebanese territory (Fig. 2).

The reserve contains the Lebanon cedar forests of Barouk, Maaser el Shouf and Ain Zhalta-Bmohray. It is an Important Bird Area (IBA) and Eco-tourism area. Since 2005 it is inscribed in the UNESCO lists as World Heritage. It hosts 32 species of wild mammals, 20 species of birds and 500 species of plants (SCR 2021).

Fig. 2 Shouf Biosphere Reserve in the study area with the polygons of the terraced areas

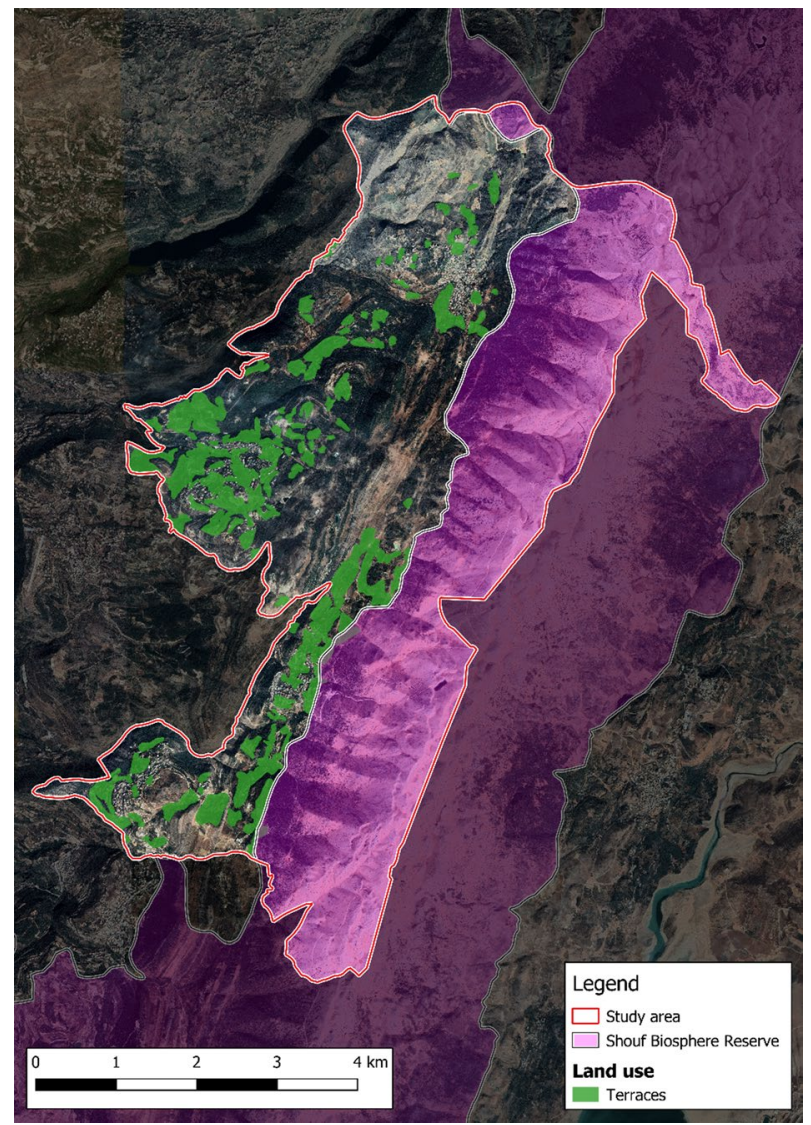




\section{Agro-biodiversity}

The SBR has a high diversity of vegetation types. Along the altitudinal gradient of the SBR mountainous landscape, a series of bioclimatic zones (Supra Mediterranean bioclimatic zone, Oro-Mediterranean bio-climatic zone) follow one another, defined by the temperature changes from the warmest basal zone to the coldest zone at the mountain summit. Each bioclimatic zone corresponds to a series of plant communities.

Today, the study area's landscape is characterized by a mosaic of agricultural land, agroforestry, semi natural woodlands and pastures (Fig. 3a). Agriculture gets the higher percentage of covering in the land use map (30\%), from which $19.4 \%$ is currently abandoned. Most forest ecosystems (16.1\%) are characterized by cedar, oak and pine species, traditionally used for wood collection, honey production, and the collection of wild edible and medicinal plants (SCR 2021).

Pastureland occupies $14 \%$ of the SBR, from which $61.5 \%$ are high mountain grasslands and $38.5 \%$ are low mountain pastures where livestock grazing is allowed. Part of low mountain pasture land is developed in abandoned terraces at the bottom of narrow valleys between the main mountainous massif and the hills that run parallel to it. They host rich flora and orchids. Shrub lands (15.5\% of the SBR surface) represent secondary vegetation that grows on abandoned agriculture terraces and degraded forest land. Rocky outcrops occupy numerous mountain slopes and hills (MoA 2020).

The majority of farmers are engaged in horticulture and fruit growing (apples, olives, cherries, peaches, pears), in addition to apiculture (cedar and oak honey, and mutifloral honey), floriculture, and the harvesting of wild plants (Fig. 3b).

Regarding apple production, it should be noted that these mainly belong to the traditional Starking and Golden groups. Historically cherry is introduced to higher shouf directly after apple, and it is more concentrated in Mrusti and Jbaa than in Maaser and Khraibe. Currently, Mrusti and Jbaa are among the strongest producers of cherries in shouf. Many farmers of Mrusti will invest in cherry trees more than in apples because the cherry production costs are lower than apple (500 LBP/Kg versus 750-1000 LBP/ $\mathrm{kg}$ ) and the selling price is double (2000 LBP/Kg) (MoE 2016).

Livestock production is also an important component of the cultural identity and food heritage of the local communities. Livestock is mainly composed of goat herds from shepherds in neighboring villages that graze in designated areas following a traditional
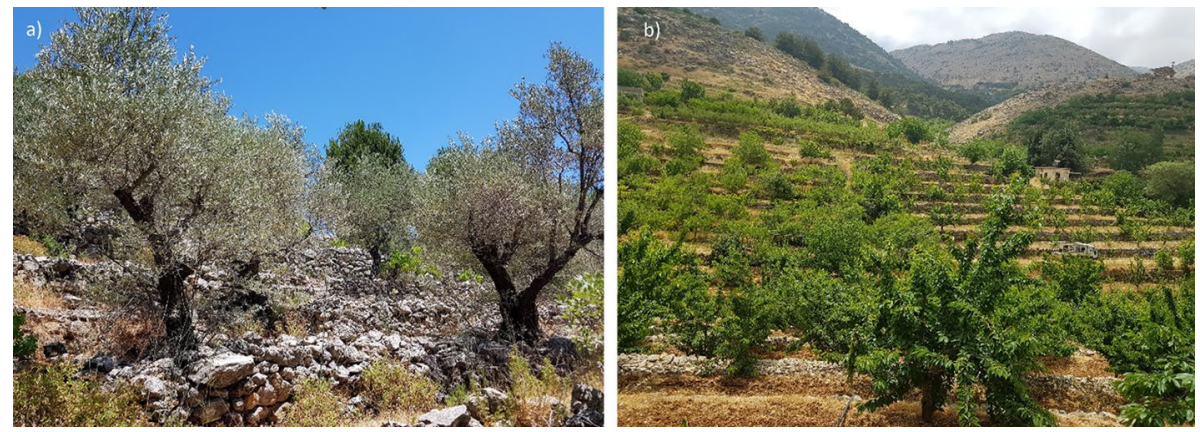

Fig. 3 a Terraces and olive trees; $\mathbf{b}$ Terraces and fruit trees 
short transhumance system (spring to autumn in the mountains and winter at lower areas outside the SBR landscape).

\section{The methodology}

The administrative borders of Lebanon were downloaded from the Lebanese geoportal site. The DTM (Digital Terrain Model), on the other hand, was downloaded from the US Geological Service site, with resolution $30 \mathrm{~m}$.

The SHP of the study area, extrapolated from the administrative boundaries, was processed in a GIS environment. Using the photo of Google Maps through Quick Map Service plug-ing, terraced land uses were identified. Terracing is an absolute necessity on the seaward side of the mountains, where slopes are steep and rainfall heavy. For this, the only way to do agriculture and survive was to build terraced systems.

Thus, starting from the assumption that all the terraced areas are cultivated, a land use map was elaborated that collects information on the presence or absence of terraced cultivation, and it was possible to elaborate the area and the geomorphological characteristics of such surfaces.

The DTM was used to calculate slope classes. It was processed using Quantum GIS 3.10.3, with the support of GRASS GIS 7.6.1 plug-in, to obtain the following informative layers: slopes, aspects and elevation class. Each characteristic was linked to each land use patch to obtain the corresponding value for each patch from these layers. At the end of this process, the attribute table of the land use layer included, for each patch, the land use categorization, the elevation class, the slope class and the dominant exposure (Santoro et al. 2020). The slope and the aspect were divided into classes to see the distribution of the two land uses (terraced and not terraced).

From the photo interpretation, it was seen that the terraces are located near infrastructures or urban agglomerations. Thanks to overpass turbo, the shapefile of the viability has been downloaded, through the key "higway" and only roads which can be driven on with vehicles have been selected. The downloaded vector file has been converted into a raster file and classified through two number codes: "0" absence of roads and "1" presence of roads. Through the "proximity" tool on GIS, a buffer was produced on the raster to highlight the distance of the terraced areas from the roads. Finally, using the function of "zonal statistics" on the land use shapefile (terraced/not terraced) was calculated the minimum value from the distances from roads.

\section{Results}

The first elaborations produced a map indicating the presence of terraced areas (Fig. 4). Only $330(8.5 \%)$ hectares out of 3809 appear terraced. However, the study area has wooded zones, where it is impossible to see the presence or absence of terraces; thus, this value is underestimated.

Analyzing the distribution of the terraced areas based on aspect, it is possible to note that they are mainly exposed to the west (164 ha-50\%). This prevalent aspect allows maximum sunlight exploitation by promoting the photosynthetic activity of crop systems. Lower distribution surfaces are found with north (105 ha), east (9 ha) and south (52 ha) aspects. Also, it should be noted that the entire study area is exposed to the north-west (82\%) since it covers the north-western side of a mountain range (Tab. 1). 
Fig. 4 Study area with terraced systems

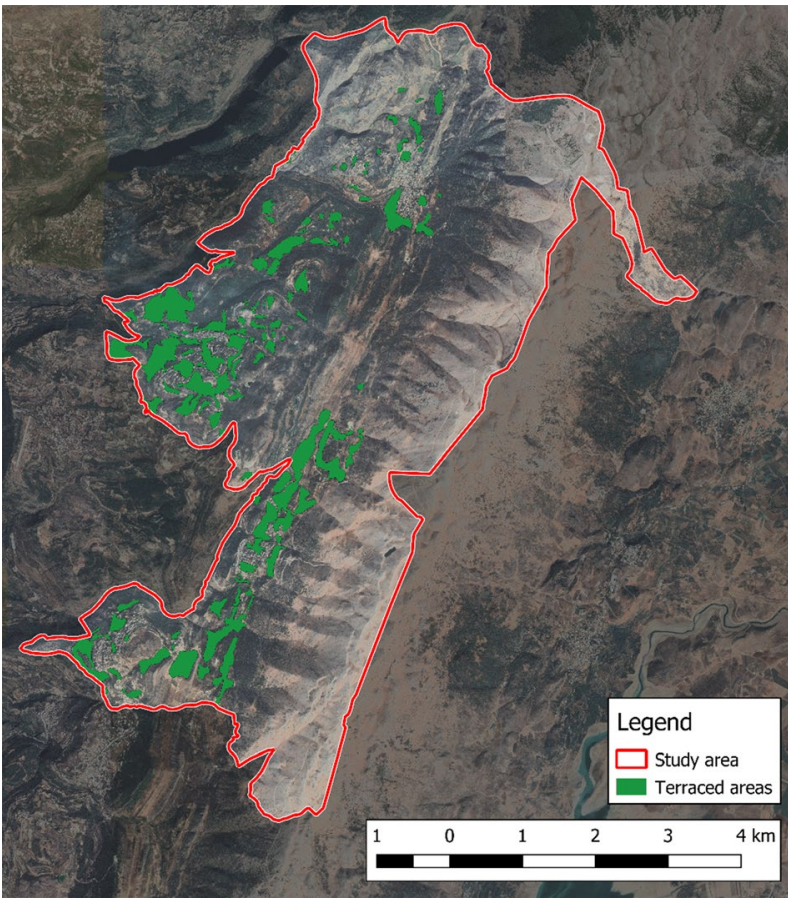

Table 1 Distribution of two land uses according to aspect

\begin{tabular}{|c|c|c|c|c|c|c|c|c|}
\hline \multirow[t]{3}{*}{ Land use } & \multicolumn{8}{|c|}{ Aspect } \\
\hline & \multicolumn{2}{|c|}{ North } & \multicolumn{2}{|c|}{ East } & \multicolumn{2}{|c|}{ South } & \multicolumn{2}{|c|}{ West } \\
\hline & $\%$ & ha & $\%$ & ha & $\%$ & ha & $\%$ & ha \\
\hline Not terraced & $25 \%$ & 880 & $8 \%$ & 269 & $14 \%$ & 487 & $53 \%$ & 1.843 \\
\hline Terraced & $32 \%$ & 105 & $3 \%$ & 9 & $16 \%$ & 52 & $50 \%$ & 164 \\
\hline
\end{tabular}

The maximum altitude of the study area is $1946 \mathrm{~m}$ a.s.1, and most of the terraced areas are distributed between 933 (minimum) to $1385 \mathrm{~m}$ (maximum). This zone corresponds to the landscape most modified by human intervention at the mountain foothills in the Supra Mediterranean bio-climatic zone, where terraces are made, due to the milder climate conditions and the geological features. The presence of deeper soils, higher soil water content and freshwater availability in that zone make it the best zone to invest in agriculture or build and live as all needs can be founded. The terraced areas are generally distributed close to urban areas or agglomerations of houses, where the slope are moderate.

In this altitudinal range, the terraced areas were intensively cultivated in the past, while now few hectares (330) of olive groves and fruit trees are still cultivated. Otherwise, secondary oak forests, mainly Quercus infectoria, mixed with Pinus brutia at lower areas in the southwestern side of the landscape have colonized abandoned agriculture terraces, becoming very dense with high dry accumulation biomass. In limestone substrates, recently abandoned agriculture terraces are colonized by species-rich communities of herbaceous plants, including several orchids, legumes and grass species. 
Preliminary work from Zurayk et al. (2000) showed that almost $66 \%$ of terraces are abandoned and the rest is planted with fruit trees like apples, figs, "umbrella" pines and grapes. On the other hand, in approximately $55 \%$ of the terraced land, irrigation is possible, meaning that there are on-site water sources, complemented with a rechargeable storage tank or man-made "birki", with an additional well or agricultural pond in few locations.

However, according to those authors, in nearly $35 \%$ of the cases, the orchards were located on natural terraces or flat depressions between escarpments and protected from erosion by their location. These fields, usually $0.5-2$ ha, are locally known as "shoab" and are very fertile as they receive run off water and sediments from their micro catchments.

Figure 5 shows that most of the terraces are distributed between 1000 and $1200 \mathrm{~m}$ a.s.l. Above $1400 \mathrm{~m}$ there are no terraces because it's difficult to grow plant species suitable for agriculture due to the mountainous climate.

The areas distributed between a hilly range from 1500 to $2000 \mathrm{~m}$ are characterized by a compact limestone substrate of the Jurassic period, forming a mountain axis with very steep slopes poorly developed soils. In these areas, in addition to not being human settlements, there are vestiges of abandoned terraces, such as in the municipality of Mrusti.

In general, the minimum altitude is higher in terraced areas than in non-terraced areas.

As regards to the distribution by inclination (Fig. 6), the terraced areas are mainly concentrated in the inclination class between $5^{\circ}$ and $15^{\circ}$ (234 ha), followed by $15^{\circ}-20^{\circ}$ ( $73 \mathrm{ha}$ ) and over $25^{\circ}$ (5 ha).

It is also possible to find areas with high inclination $\left(52^{\circ}\right)$, but the terracing was found on an area with a maximum slope of $41^{\circ}$ (Table 2).

The terraced areas are distributed near urban centres or agglomerations of houses. These built-up areas are built in accessible zones; consequently, the terraces are also on gentler slopes.

Figure 7 and Table 3 shows the mapping of the distances of the terraced areas from the connecting roads. The results confirm that most of the terraced patches are located within $50 \mathrm{~m}$ of the country roads (65\% of all the terraced patches). Many of the terraced areas are also actually crossed by them. There are very few patches (20), in orange and red color, mainly in the study area's central part, found at distances ranging from $200 \mathrm{~m}$ up to $660 \mathrm{~m}$. The lack of terraced areas and connecting road infrastructures is evident on the eastern side of the area. It is also interesting to notice that the average patch size follow a specific trend: in the nearest classes, the patches results wider, with an average patch size of 3,7 ha, while

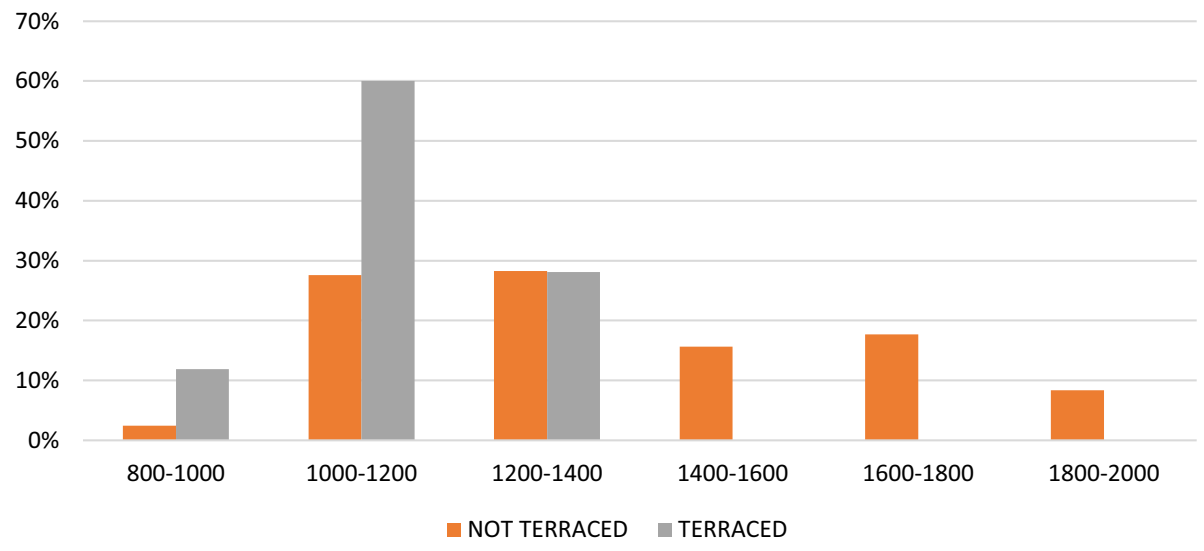

Fig. 5 Distribution of land uses of the study area according to altitude classes 


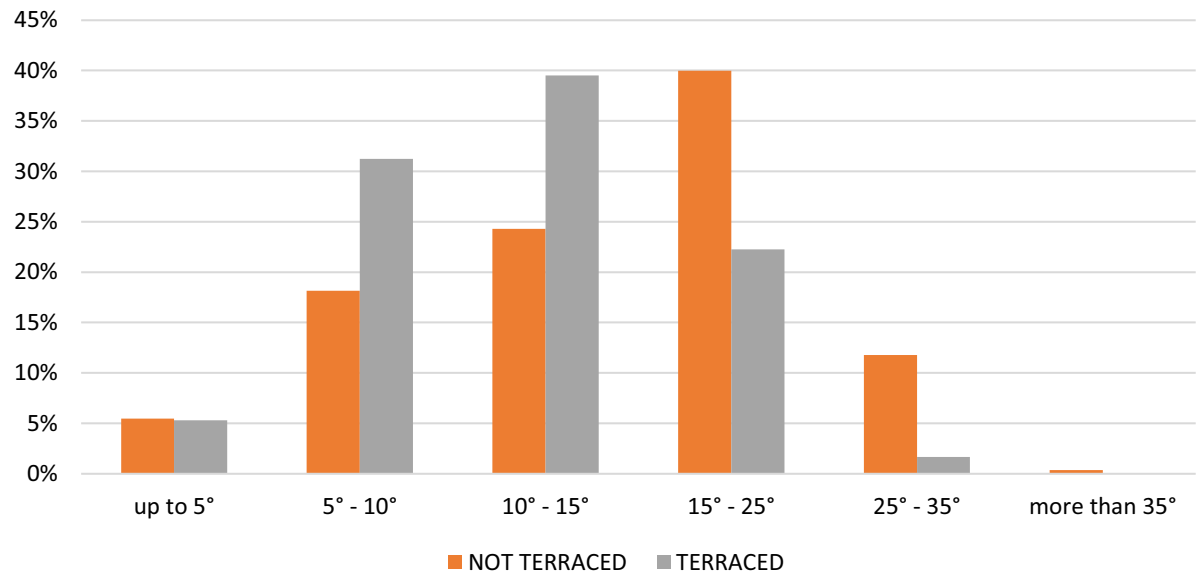

Fig. 6 Distribution of land uses of the study area according to inclination classes

Table 2 Average and maximum inclination of the area

Fig. 7 Maps of the distance of terraces from roads

\begin{tabular}{lll}
\hline Land use & Inclination & \\
\cline { 2 - 3 } & Average & Maximum \\
\hline Not terraced & $18^{\circ}$ & $52^{\circ}$ \\
Terraced & $13^{\circ}$ & $40^{\circ}$ \\
\hline
\end{tabular}

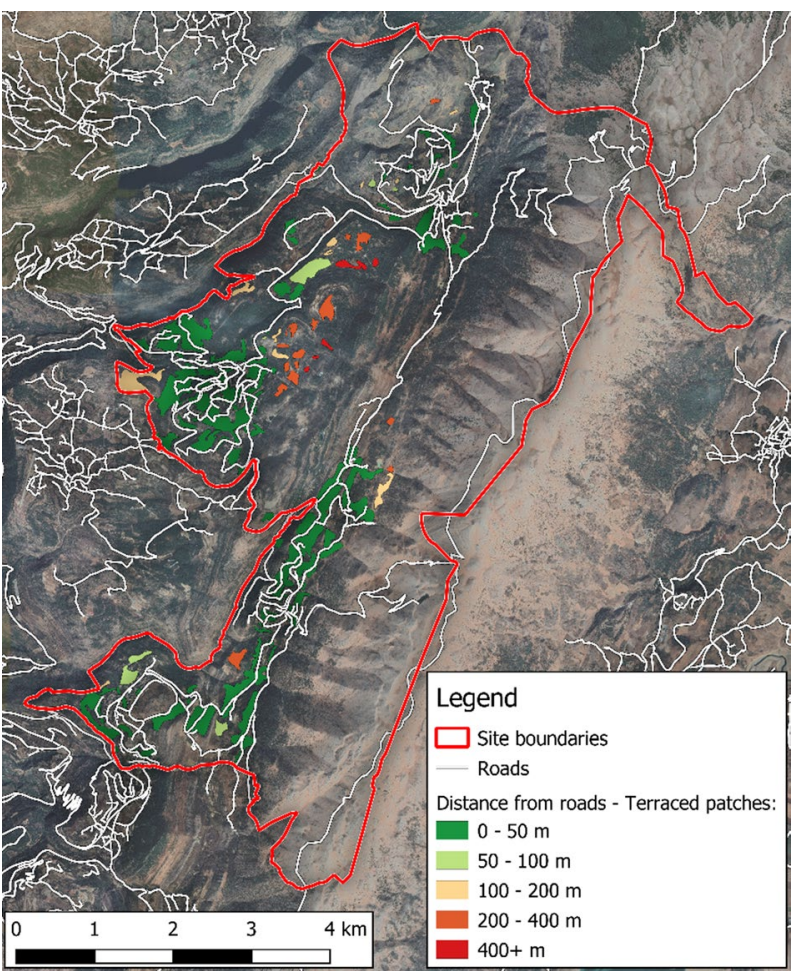


Table 3 Terraced patches distribution in classes of distance from roads

\begin{tabular}{|c|c|c|c|c|c|}
\hline \multirow[t]{2}{*}{ Distance class } & \multicolumn{2}{|c|}{ Surface } & \multicolumn{2}{|c|}{ Patches } & \multirow{2}{*}{$\begin{array}{l}\text { Avg. patch } \\
\text { size (ha) }\end{array}$} \\
\hline & $\mathrm{Ha}$ & $\%$ & Count & $\%$ & \\
\hline $0-50 \mathrm{~m}$ & 260,7 & 82 & 71 & 65 & 3,7 \\
\hline $50-100 \mathrm{~m}$ & 16,1 & 5 & 7 & 6 & 2,3 \\
\hline $100-200 \mathrm{~m}$ & 19,2 & 6 & 12 & 11 & 1,6 \\
\hline $200-400 \mathrm{~m}$ & 19,4 & 6 & 15 & 14 & 1,3 \\
\hline $400 \mathrm{~m}$ or more & 4,4 & 1 & 5 & 5 & 0,9 \\
\hline Total & 319,8 & & 110 & & 2,9 \\
\hline
\end{tabular}

the distant classes have smaller patches, up to 0,9 ha for the most distant. The presence of roads thus can be linked not only to the presence or absence of those kind of systems, but also to the size of these patches, helping to maintain and cultivate wider terraces.

In the terraced areas in a state of abandonment but with a high degree of accessibility, the hypotheses of restoration of the dry stone walls and new cultivation of the terraced strips can be positively evaluated from an economic point of view.

\section{Discussion}

This research presents a preliminary investigation regarding the terraced heritage of SBR, offering a picture of the current situation of a peculiar landscape and the associated biodiversity.

These terraces are examples of how man is able to model and adapt to critical habitat and provide income and livelihood for the locals. Terracing is one of the most striking artificial features dominating the highland agricultural landscapes of the southern Levant. Much human effort has been made to build these hundreds of thousands of terraces to meet the community's food needs by creating arable land for fruit trees and other crops. The slopes around the villages of Shouf district, especially high altitude ones like those of the study area, were intensively terraced and cultivated since ancient times to produce vines, olives, mulberries, walnut and almond trees in addition to figs and grains.

Nowdays the main vulnerability seems to be the land abandonment. The migration of a large part of the population during and after the war caused the abandonment of many cultivated lands with the consequent destruction of the ancient agricultural terraces and the beginning of erosion phenomena (e.g. loss of fertile soil and increase of runoff). In the most favorable situations, terraces were colonized by secondary vegetation (stages of plant succession from pastures to thickets and forests, according to the time of abandonment) that today accumulates much dry biomass and carries a high risk of fire. In the worst cases, the dry-stone wall collapse damages the land below and makes a loss of biodiversity and landscape deterioration.

A minor blemish in Shouf district can be found; it is the unclear delimitation of land tenure and the absence of land use planning in the SBR landscape. There are also uncontrolled urbanization and mining activities in the Biosphere Reserve buffer zone and in some parts of the core zone. The accelerated urbanization process is also due to the remittances sent by Lebanese emigrants who live abroad but want a home in Lebanon. The abandonment of the customary governance systems that regulated the management of natural resources in communal and public lands has led to conflicts among land users and the overexploitation 
of the natural ecosystems and wildlife.Falling population dynamics are also behind the degradation of the landscape.

In any case, the Shouf terraces are representative of an example of human adaptation to nature, supporting local communities by ensuring food security.

Observing the difference between cultivated and non-cultivated areas, we can see how the elements tipically considered disturbing, such as the connecting roads, are necessary to generate a sustainable integrated development and promote the local population's resilience. Sustainable development policies for dynamic landscape conservation can achieve these goals of preserving biodiversity through traditional local agricultural practices in the framework of the biocultural diversity characterizing the area (Agnoletti and Rotherham 2015).These principles are receiving attention at the international level from FAO with the Globally Important Agricultural Heritage Systems (GIAHS) program and could be adopted for the SBR.

The inclusion of the BSR in the GIAHS program would represent an excellent opportunity to increase the local population's quality of life, mainly through cultural identity, a sense of place, and the dissemination of knowledge of traditional local practices applied to agricultural activities. These criteria, added to well-structured social organization systems, can effectively contribute to precarious local agricultural systems' resilience, balancing environmental and socio-economic needs.

\section{Conclusion}

The results showed that terraced systems occupy $8.5 \%$ (3809 ha) of the SBR. The predominant land cover is agricultural, with olive groves and fruit trees, even if a mosaic of agricultural landscape characterizes it. The terreaced systems analysis showed that the aspect classes most represented are those to the west (50\%) and north (32\%). The altitude range is distributed between 100 and $1400 \mathrm{~m}$, and the inclination classes most represented are comprised between $10^{\circ}$ and $25^{\circ}$. Since the heterogeneity found in this terraced area concerns many aspects, from the ecological biodiversity to the landscape mosaic, a globally recognized reserve should acknowledge and ensure it. The terraces themselves, with various types of stones and different arrangements, constitute a source of biodiversity because they allow having a diversified landscape mosaic that gives an added value to the environment. The study area represents a unique environment where the local community has generated a sustainable agricultural system that respects nature and landscape, maintaining traditional agricultural practices.

From results, the easy access to terraced areas appears to be of vital importance for their conservation; indeed, most of the terraced areas are within $50 \mathrm{~m}$ of the roadway. The possibility of a driveway access to the cultivated areas allows better maintenance and more excellent usability of the land. Few terraces were found at distances greater than $200 \mathrm{~m}$, and the maximum distance never exceeds $700 \mathrm{~m}$. Thus, since most of the roads are concentrated on the western side of the study area, the terraces are also in the same areas. According to this preliminary step, future research will be focused on investigating the state of conservation of dry-stone walls, trying to find out a possible correlation between the distance from the roadway and water management, biodiversity and soil conservation.

The current landscape of the SBR is the result of the transitory interactions between the local community and its improperly managed resources. Terraced landscapes, in particular, are a representative case of the need to face management of the territory that aims to strengthen the relationship between man and nature, thus avoiding the phenomenon of abandonment. For this reason, agriculture can contribute to the sustainable management of 
resources, to the conservation of biodiversity, and to maintaining the economic and social vitality of rural areas (OECD 1998).

Author contributions Conceptualization, F.C., L.C., M.F.; methodology, F.C., F.P.; investigation, F.C., L.C., F.P., M.A.A.; writing, L.C., F.C., F.P.; supervision, L.C.

Funding Open access funding provided by Università degli Studi di Firenze within the CRUI-CARE Agreement. This research is part of the "GIAHS Building Capacity" project, funded by the Italian Agency for Development Cooperation (AICS) and by the Department of Agriculture, Food, Environment and Forestry (DAGRI) of the University of Florence.

\section{Declarations}

Conflicts of interest The authors declare no conflict of interest.

Open Access This article is licensed under a Creative Commons Attribution 4.0 International License, which permits use, sharing, adaptation, distribution and reproduction in any medium or format, as long as you give appropriate credit to the original author(s) and the source, provide a link to the Creative Commons licence, and indicate if changes were made. The images or other third party material in this article are included in the article's Creative Commons licence, unless indicated otherwise in a credit line to the material. If material is not included in the article's Creative Commons licence and your intended use is not permitted by statutory regulation or exceeds the permitted use, you will need to obtain permission directly from the copyright holder. To view a copy of this licence, visit http://creativecommons.org/licenses/by/4.0/.

\section{References}

Aalen FHA (2001) Landscape development and change. In: Green B, Vos W (eds) Threatened landscapes, conserving cultural environments. Spon Press, London, pp 3-20

Abu-Izzeddin F (2017) Shouf Biosphere Reserve Management Plan 2012-2017, internal report prepared for the Shouf Biosphere Reserve Society. http://shoufcedar.org/wp/wpcontent/uploads/2017/06/Annex-8Shouf-Biospherec-Management-Plan-2013.pdf

Agnoletti M (2014) Rural landscape, nature conservation and culture: Some notes on research trends and management approaches from a (southern) European perspective. Landsc Urban Plan 126:66-73

Agnoletti M, Rotherham ID (2015) Landscape and biocultural diversity. Biodivers Conserv 24:3155-3165. https://doi.org/10.1007/s10531-015-1003-8

Agnoletti M, Conti L, Frezza L, Monti M, Santoro A (2015) Features analysis of drystone walls of Tuscany (Italy). Sustainability 7:13887-13903. ISSN: 2071-1050. https://doi.org/10.3390/su71013887

Arnaez J, Lasanta T, Errea MP, Ortigosa L (2011) Land abandonment, landscape evolution and soil erosion in a Spanish Mediterranean mountain region: the case of Camero. Land Degrad Dev 22:537-550

Di Fazio S, Modica G (2018) Historic rural landscapes: sustainable planning strategies and action criteria. The Italian experience in the global and European context. Sustainability 10(11):3834. https://doi.org/ $10.3390 /$ su 10113834

Diane AM, Brandon PA (2010) Application of modified threat reduction assessments in Lebanon. Conserv Biol 24(5):1174-1181. https://doi.org/10.1111/j.1523-1739.2010.01575.x

Diane AM, Brandon PA (2019) Sense and sustainability: the story of biosphere reserves in Lebanon. UNESCO biosphere reserves: supporting biocultural diversity, sustainability and society, chapter: 11. Earthscan, London. https://doi.org/10.4324/9780429428746-11

Dunjó G, Pardini G, Gispert M (2003) Land use change effects on abandoned terraced soils in a Mediterranean catchment, NE Spain. CATENA 52:23-37

FAO (2020b) Evaluation of FAO's country programme in Lebanon-2016-2019. Country Programme Evaluation Series. 06/2020. Rome. ISBN: 978-92-5-132892-7.

FAO (2020a) Special report-FAO mission to assess the impact of the financial crisis on agriculture in the Republic of Lebanon. FAO, Rome. https://doi.org/10.4060/cb1164en

Ghattas H, Barbour JM, Nord M, Zurayk R, Sahyoun NR (2013) Household food security is associated with agricultural livelihoods and diet quality in a marginalized community of rural bedouins in Lebanon. $\mathbf{J}$ Nutr 143(10):1666-1671. https://doi.org/10.3945/jn.113.176388 
Lasanta T, Paz Errea M, Nadal-Romero E (2017) Traditional agrarian landscape in the mediterranean mountains. A regional and local factor analysis in the central spanish Pyrenees. Land Degrad Dev 28:1626-1640

Laureano P (2007) Traditional Knowledge for the safeguard of rural landcape. In: Landscape and rural heritage, Proceedings of the sixth meeting of the workshops of the council of Europe for the implementation of the European Landscape Convention, Sibiu, Romania, 20-21 September 2007; Council of Europe Publishing Editions: Strasbourg, France, 2007, pp 303-308

Lewis NN (1953) Lebanon. The mountain and its terraces. Geogr Rev 43(1):1-14

Markou M, Kavazis A (2006) Market and trade policies for mediterranean agriculture: the case of fruit/ vegetable and olive oil Agricultural Situation Report-Lebanon. Agric Res Inst Nicos. https://doi.org/ 10.13140/RG.2.1.1063.8487

Ministry of Agriculture (MoA), Lebanese Republic. Lebanon National Agriculture Strategy (NAS) 20202025. http://www.agriculture.gov.lb/getattachment/Ministry/MinistryStrategy/strategy-2020-2025/ NAS-web-Eng-7Sep2020.pdf?lang=ar-LB

Ministry of Environment MoE/UNDP/GEF (2016) Lebanon's third national communication to the UNFCCC. Beirut, Lebanon. http://climatechange.moe.gov.lb/viewfile.aspx?id=239

Modica G, Praticò S, Di Fazio S (2017) Abandonment of traditional terraced landscape: a change detection approach (a case study in Costa Viola, Calabria, Italy). Land Degrad Dev 28(8):2608-2622. https:// doi.org/10.1002/ldr.2824

OECD (1998) Multifunctionality, a framework for Policy Analysis, OECD, Agr/CA/98

Santoro A, Martinex Aguilar EA, Venturi M, Piras F, Corrieri F, Quintanilla JR, Agnoletti M (2020) The Agroforestry Heritage System of Sabana De Morro in El Salvador. Forests 11:747. https://doi.org/10. 3390/f11070747

Shouf Cedar Reserve (SCR) (2021) Natural heritage. SCR, Lebanon. http://www.shoufcedar.org. Accessed Feb 2021

Tarolli P, Preti F, Romano N (2014) Terraced landscapes: from an old best practice to a potential hazard for soil degradation due to land abandonment. Anthropocene 6:10-25

United Nations (2015) Tranforming the World: the 2030 Agenda for sustainable development. https://sdgs. un.org/publications/transforming-our-world-2030-agendasustainable-development-17981

Zurayk R, el-Awar F, Hamadeh S, Talhouk S, Sayegh C, Chehab A-G, al Shab K (2000) Using indigenous knowledge in land use investigations:a participatory study in a semi-arid mountainous region of Lebanon. Agric Ecosyst Environ 86(2001):247-262

Publisher's Note Springer Nature remains neutral with regard to jurisdictional claims in published maps and institutional affiliations.

\section{Authors and Affiliations}

\section{Federica Corrieri ${ }^{1} \cdot$ Francesco Piras $^{1} \cdot$ Marwa Abou Assi $^{2} \cdot$ Marco Focacci $^{3}$. Leonardo Conti ${ }^{1}$ (i)}

Federica Corrieri

federica.corrieri@unifi.it

Francesco Piras

francesco.piras@unifi.it

Marwa Abou Assi

marwa.abouassi@gmail.com

Marco Focacci

marco.focacci@aics.gov.it

1 Department of Agriculture, Food, Environment and Forestry (DAGRI), University of Florence, via San Bonaventura 13, 50145 Florence, Italy

2 Student of the Master Course "Agricultural Heritage Systems", University of Florence, Florence, Italy

3 Italian Agency for Development Cooperation, Rome, Italy 